\title{
Jurisliterature and Transgression
}

By Peter Goodrich (Professor of Law and Director of the Program in Law and Humanities at Cardozo Law School, New York, and Visiting Professor of Law School of Social Science, New York University Abu Dhabi), Orchid: https://orcid.org/0000-0001-8013-5850

Cardozo Law School and New York University Abu Dhabi

\begin{abstract}
The jurisliterary profession is the curious enterprise of writing, as a jurist, about law. Many seek to escape into literature, philosophy, critique, psychoanalysis, the couch, but then, in the main, they have abandoned law. Those that persist, who remain jurists, have the propensity to transgress the boundaries of the juridical, the strictures of abstraction and disembodiment, so as to generate accounts of legal sensibility, so as to manifest the polyglottal and visceral potential of transforming the juridical bubble into that most ethical of realms, the poetics of desire. Jurisliterary transgression, at its strongest, returns the materiality of imagination to the sensorium of legality.
\end{abstract}

\section{Keywords - jurisliterature, transgression, community of intellect, Twitter, Shakespeare, Bowdler}

Acknowledgements. Thanks to Pompeu Casanovas i Romeu for remembering, after so long, how we met in a small motel on the East Coast of the United States at an obscure roundtable of semiotics of law, for alerting me to histrionic tendencies at the semiotics conference in Helsinki, for opening up his house in Barcelona, and much later, for inviting this contribution. My thanks to Nicholas Morris for his meticulous edit and selfless passion for sub-headings.

Disclosure statement - No potential conflict of interest was reported by the author.

License - This work is under Attribution-NonCommercial-ShareAlike 4.0 International (CC BY-NC-SA 4.0) https://creativecommons.org/licenses/by-nc-sa/4.0/ Suggested citation: Goodrich P. (2020). “Jurisliterature and Transgression”, Law in Context, 36 (2): 10-16. DOI: https://doi.org/10.26826/law-in-context.v36i2.111

\section{Summary}

1. The spirit of inquiry

2. The immobilisation of legal language

3. A multiplicity of discourses

4. The importance of context

5. The uses of literature

6. Transgression upon transgression

7. References

What more Rogues still? I thought our happy Times Were freed from such, as from Rebellious Crimes. But such will be: in the best of Times we find The worst of men; the Law can't lawless bind. 


\section{THE SPIRIT OF INQUIRY}

My most recent manuscript, if a personal aside is permissible, Skeletons of Amity: Lives Lived in Exodus from Law, is currently with the publisher's lawyers. I am not sure when, or if, it will emerge. Too many names, too many personal observations, accolades or calumniations, according to one's perspective, drawn from my intimate archive. I like to think it is because I write what I want or at least I try to be ethical, to remain true to my desire. There is body and autobiography, libidinal economy and the tensor of affect in all that we do. I mention this because recognition of enjoyment, the will to knowledge, the putting of ignorance to work, the play of enthusiasm, the haptic and intellective pleasure of reading and writing, of teaching and learning, are too seldom confessed, too infrequently given their due. There is a tendency to be cautious, often fearful of admitting that as scholars, pedagogues, dissertation supervisors, pastoral incumbents of academic office hours, or professing from podia and other seminary lecterns, or currently Zooming, our privilege lies in significant part in the desire fulfilled in choice of text, of theme, of interlocutor, of screen and page. We want what we write, to pierce our unknown, to fracture preconceptions, to cross the line, find something out. Even here, even this.

The spirit of inquiry, what Anthony Ashley Cooper (third Earl of Shaftesbury) termed 'enthusiasm' [1714], gains expression in varied modes of invention and discovery, as insight, a flash of light, a eureka moment, or an epiphany. ${ }^{1}$ What these moments share is not simply the tensor and libidinal excitation of interior augmentation, the molecular, circulatory and visceral events of passage but also and more symptomatically a sense of an outside which suddenly manifests, a spectral apparition that appears to the eye of intellection. Be it an unexpected connection, an intensity, a rare syncretic apposition, the enthusiasm and enjoyment come from the opening of the subject to another, an exterior, an event that exceeds and changes how one hears, views, reacts and embodies change. It is most explicit in the annunciative quality of epiphany which can be understood best in the profane sense of opening to something more than the self, more than the discipline or prior thought. It is a transformative instance, an event, perhaps a minor one, of encounter with the vast collectivity of thought, the communality of shared intellection. ${ }^{2}$ We open to the living quality of an entity, a being, an artefact, even an object in its visceral materiality, as living matter, Gaia.

\section{THE IMMOBILIZATION OF LEGAL LANGUAGE}

To my point, however, which is a more restricted one. In the conspectus of disciplines law is one that has historically inhabited or at least endeavoured to project a closed space. It has effectuated such constriction, as Extabe (2020) has recently argued, most effectively through the immobilization of legal language and an analytic schema that reduces utterances to sentences divorced from context, speaker, interlocutor, auditor or reader. ${ }^{3}$ The transgressions, affects, exposures, openings of dialogue, the embrace of communities, historical and future that every utterance engages, the tones and timbre, laughter, frisson, blush and rage that interlocution, the act, which is to say the performance that every utterance instigates is excised from view and suppressed from analysis. For jurisliterature, the study of literary or, better, literate lawyers and the openness of their language, the inventiveness of figure, plot, image and the whetstone of their wit, is the intended focus and surplusage of their essential literarization of legality. The maelstrom of every unfinished text—of each and all utterances - is a symptom of desire, a figure of quiet or exothermic transgression of the unstable and impossible, putative boundaries of the professional argot of law. ${ }^{4}$ Jurisliterature is what jurists write. It could not be anything else. But it is also a conflation of fiction and law, a breaching of the boundaries of genres and most specifically a battle against abstraction and the attempted closure of the language of law. To transgress is to trespass and as Foucault reminds us, it is to step beyond, to pass over a line, to cross a boundary and then and crucially to return, to see the liminal demarcation close up again, but changed, revised, rejuvenated, for good or ill. Anyone who writes, whether lawyer, bureaucrat, politician, epistolary novelist, orator or thespian is engaged, though differently, in language, and so in utterance, dialogue, acting and performing in literary modes. What differentiates the lawyer who remains a lawyer is that they do not leave the juridical register, they resist the desire to escape into literature or poetics which, according to Quintilian is only their respite and pleasure upon retiring from law (Tacitus 1911). ${ }^{5}$ Until release, jurisliterature inhabits the borderline signified by the elision

\footnotetext{
${ }^{1}$ Cooper, A.A. [Third Earl of Shaftesbury].1999. Characteristics of Men, Manners, Opinions, Times [1714] edited by L.E. Klein, Cambridge: Cambridge University Press.

2 Bottomley (2000) provides a powerful account of the visceral and perhaps exothermic character of theory. Davies (2017) takes up these themes in the spirit of the new materialism, and there should always be room for mention of Watt (2013). 3 Julen Extabe (forthcoming) provides a powerful account of the dialogism of legal language as undercutting the sense of legal closure and juristic autonomy. There is also inspired discussion, with particularly acute emphasis on carnival, fools, clowns and rogues in Desmond Manderson (2016). ${ }^{4}$ Anne Tessier-Ensminger (2015) at 7: "the term 'jurisliterature' ... is an attempt to show the complementarity of two tropisms of writing ..." refusing in effect to accede to the desire of either to absorb the other in the interests of promulgating its own specificity and, likely as not, superiority. ${ }^{5}$ AlthoughthetraditionalattributionoftheDialogueofOrators (London:LoebClassicalLibrary, 1911)to Tacitusisprobablyincorrect,andtheauthorisQuintilian. SeeBrink(1989).
} 
of the terms, denizens of the back and forth of transgression and return between law and its extimate spheres, and here the liminalities that distinguish law and literature while imbricating each in the other.

The first point to make is simply that of the complementarity of the disciplines as textualist endeavours. Jurisliterature may be afflicted by aspersions of marginality or professional superfluity - literature is not law - but the truth is that while law may often be bad literature or poorly written and of little poethical value and valence, it cannot but be literature, dialogic utterance gauged to an audience, interlocution in which invention and imagination, style and tone play their unavoidable roles. ${ }^{6}$ Such a depiction, however, is in quotidian contexts that of work that does not transgress, texts of the everyday literature of law, the blandly prosaic or simply muddled expressions of administrative protocol and decree. These are the texts, the legislations and precedents that literature in transgression of the formidable and forbidding thresholds of law seeks to return, revise and rewrite. Escaping from law, exodus from legalism is constituted most often by the search for an 'other', a poetry, literature, art or image that will reimagine those spaces of merely administrative textual practice where law is all used up, exsuccuous, poorly written, weakly uttered. Take an example of which I am fond, where a multiplicity of discourses seeks to play the law.

\section{A MULTIPLICITY OF DISCOURSES}

In $D P P v$ Chambers at least four genres of literature interact and at times conflict: tweets, statutory edicts, judicial deliberations and drama in the form of a citation from Shakespeare. It forms a fertile ground for analysis, a species of test case for the theory, akin to Derrida's position in the force of law, but more specific, that transgression, entry into another language, crossing the line of the legal prose for the allegorical force of literature is the only mode in which justice-poethical decisions, jurisliterary texts-can be created.

The issue prosecuted, appealed and then appealed again was a novel mode of utterance on a new platform, Twitter. Using the microblogging, 140 character limit, platform, the twitter handle @PaulJChambers, the appellant, living in the North of England, had been due to fly to Belfast on January 15 to meet a tweep friend, whose handle was @Crazycolours. A week before he was due to fly, Doncaster Robin Hood Airport was closed due to snow and an exchange relating to the closure ensued:
@Crazycolours: I was thinking that if it does then I had decided to resort to terrorism.

@ Crazycolours: That's the plan! I am sure the pilots will be expecting me to demand a more exotic location than NI [Northern Ireland].

@PaulJChambers: 'Crap! Robin Hood Airport is closed. You've got a week and a bit to get your shit together otherwise I am blowing the airport sky high!!

After some deliberation, the Crown Prosecution Service decided to charge Paul Chambers under sections 127(1)(a) and (3), for so it is writ, of the 2003 Communications Act, with "sending by a public electronic communication network a message of a menacing character". ' Chambers was convicted in the Magistrates' Court and fined a total of $£ 985$. He lost his job as a consequence. The conviction was appealed but upheld by Judge Jacqueline Davies of Doncaster Crown Court. She castigated Chambers as an "unimpressive witness" and his evidence as "self-serving", concluding that the tweet was "menacing in its content and obviously so. It could not be more clear. Any ordinary person reading this would see it in that way and be alarmed." Chambers, in other words, "in the present climate of terrorist threats, especially at airports, could not be unaware of the possible consequences". ${ }^{8}$ He was ordered to pay a further $£ 2000$.

The decision resulted in major media and twitter protests, with Stephen Fry offering to pay the fine and the costs of appeal, and numerous journalists pouring scorn on the Judge's failure to comprehend Twitter, tweets and tweeps, while also lacking any appreciation of the parodic character of the posting. The agelastic determination managed the extraordinary feat of turning a joke into a crime. It was this crowdsourced, cloud based protest that produced a final appeal to the High Court where, before the appropriately named Judge Judge, the conviction was finally overturned on the grounds that noone responding to the message, neither airport security nor the South Yorkshire Police, nor the rather lame 630 tweep followers of @PaulJChambers had in fact been unduly disturbed by the 108 characters of the posting. When it comes before Judge Judge to be judged, the suit has something of the character of a test case on use of the new medium, the meaning of the short message, the context and socio-linguistic impact of the tweet which, after all, was sent a week before the planned travel to visit the avatar or handle @crazycolours.

A new medium dictates a novel discourse, a different language and here most obviously transgression of the gravitas

\footnotetext{
${ }^{6}$ Richard Weisberg (1992) at 4: "the carefully crafted utterance (in law and literature) unites the message with the medium-indeed, is so constituted that the medium of linguistic expression is the meaning".

${ }^{7}$ Chambers $v$ Director of Public Prosecutions [2013] 1 All ER at 150.

${ }^{8}$ The Guardian, Thursday 11 Nov 2010 (Paul Wainwright).
} 
of law. It poses a threat most immediately in being outside and other to the language of law, an extimacy that seemingly escapes juristic comprehension, a fact that is sometimes noted by the judiciary, although not in this instance. ${ }^{9}$ The use of Twitter by @PaulJChambers and @crazycolours is transgressive in the event both as a form and as a message that includes reference to terrorism, hijacking, and exothermic fulminations. It is in a double sense external to law, transgressive of medial boundaries as also of the limits of legal language, infracting perhaps the ludic prohibition in Roman law of jokes and of play (artem ludicram) in public forums. ${ }^{10}$

More than that, a third transgressive feature lies in the reversal of the discursive hierarchy in which the serious social speech of law is handed down a one way street from the Judge to the Court, author to auditor, in the traditional form of juridical edicts and promulgations. Here, however, the public and media outcry, the pandemonium on Twitter, the microblogged maelstrom of critiques of the conviction in the Magistrates' Court and then the Crown Court drove the case to the High Court and clearly influenced the decision, not least because 'ordinary people' were manifestly more threatened by the judges' incomprehension of new media than they were by the tweets under interdiction. What is transgressive is not the diffraction of discourses, the incomprehension manifested between old and new media, forensic text and social media, but rather that the extra-legal in this instance came to play a dominant yet unacknowledged role in the decision. ${ }^{11}$

\section{THE IMPORTANCE OF CONTEXT}

Context transgresses the literality of law, indeed, to coin a phrase, it 'cons the text', it tricks legality and dethrones legalism. Judge Judge-I can't resist-makes a dismissive reference to the syntactic inadequacy or simple semantic paucity of Twitter, remarking of the tweet in question that "The language and punctuation are inconsistent with the writer intending it to be or to be taken as a serious warning."12 It would appear to have been discursively inadequate, grammatically deficient, as a threat. To say that terrorism is ineffective when syntactically incorrect is almost absurd unless one interprets the Judge symptomatically as deflecting from the key transgression which is that in the absence of law, in the incalculable moment of judgment, in the 'High' Court, polysemy intended, it is precisely the extra-juridical, the everyday of social media and internet relay, the strange world of post-law that takes the reigns and decides the case. The Judge cannot say that this is a matter for popular decision, for an informal vote, for democratic populism, but that is the context that necessarily drives the particularity of the determination.

There is ample and commendable literature on the input of audio visual links, of internet communication, of pixelated protagonists impacting courts and trials but these are generally functional technical aids to legal control, versions of a virtual panopticon, whereas the case of Twitter is the inverse, a domain that is out of legal control, that recursively and sometimes violently turns on the law and redraws its boundaries in the umbrageous and sciographic form of a shadow revision of the sensible site that it supposedly reflects. ${ }^{13}$ That form is the law, but it transpires that the legislative sources for determination of the relevant offence predate the invention of Twitter in 2006. More than that, the 2003 Communications Act and its definition of network messages of a "menacing character" is in fact a simple repetition and legislative updating of the Post Office (Amendment Act) 1935, s 10(2)(a) which "introduced a prohibition against the misuse of the telephone to communicate indecent, obscene or menacing messages". Aimed primarily at obscenities directed to individual female exchange telephonists over the wires, the sense of menace indicated by the earlier context and limited technology is clearly and avowedly impertinent to the agon of Twitter and flirtatious tweets. The recirculation of the offence in the 2003 Act simply placed the same menace in the context of what were then new media and rather quaintly depicted by Judge Judge as having "now advanced to the present electric communications networks". Passing over the fact that electric communications, meaning the animated, lively, affective tensors of libidinal expression directed on this occasion, as fortuity would have it, to @crazycolours seems to be precisely what two out of three courts expressly did not want, the landline becomes the juristic cover for jurisliterary invention and for a lawless law. ${ }^{14}$

\footnotetext{
${ }^{9}$ In HM Attorney General v Kasim Davey and Joseph Beard [2013] EWHC 2317, for instance, the President of the Queen's Bench states: “Indeed, you may have heard about the juror who went on Twitter or is it Facebook - I am afraid I am on neither - I may be discussed there, but I am not on either ...”

${ }^{10}$ The ban on jokes is most notoriously to be found in the Digest of Justinian [CE 530-533] (Watson1985), at liii-liv making jokes a crime (iniuria est ludos exercere) and also, at xliv (De Conceptione digestorum) forbidding commentaries and interpretations of the written law.

${ }^{11}$ For an excellent analysis of this reversal of trajectory, see Carr and Cowan, (2016); and see also the discussion in Delage et al. (2019) ch. 1.

${ }^{12}$ Chambers $v$ DPP, at 158.

${ }^{13}$ For work on AV links to courts and to prisons, see, for example, the work of McKay (2018); and Castañeda (2019).

${ }^{14}$ A lawless law, the editor has suggested some expatiation, references a law without transgression, a law without a material purpose, a law which in Hegel's argot, is without Law, arbitrium that blandly follows a corporate rule.
} 


\section{THE USES OF LITERATURE}

The bulk of the judgment of Judge Judge is deflective, manipulating the disposif of the statutory text to provide the phantasmagoria of legislative provision for what were then non-existent relays. The lengthy, wearisome, boring, and largely irrelevant citation to the Statute, to clauses that are nowhere pertinent to the question of what 'a message of a menacing character' means, section 127(1)(b) and (c) for instance with which the reader is regaled or rather rebuffed, for instance, serves the purpose of juristic persiflage, distraction from the actual grounds of decision, which are jurisliterary and emerge in paragraph 28 of the judgment. Arriving finally at a discussion of the provenance and purpose of the relevant subsection of 127(1), which is (a), the Judge veers without introduction or explanation, into literature. First, it is political opinion that is cited, the unlikely figure of President Roosevelt is invoked as advocate of "essential freedoms", what non-English common law would term rights, as including "freedom of speech and of expression" ${ }^{15}$ Why Judge Judge judges Roosevelt the relevant source, rather than the established jurisprudence of the First Amendment is enigmatic but less to the point than that the judgment has virulently left the discourse of law for the language and literature of politics as legitimation of the view that "[s]atirical, or iconoclastic, or rude comment, the expression of unpopular or unfashionable opinion about serious or trivial matters, banter or humour, even if distasteful to some or painful to those subjected to it should and no doubt will continue at their customary level, quite undiminished by this legislation." ${ }^{16}$ Which is a peculiar thing to say insofar as it persists in the strategy of the judgment to address everything that the law does not regulate and about which the legislation has nothing to say. It is precisely the gap, the novelty, the lawless escapade and sudden exodus from the lengthily cited, dull and distracting legislative text that is of key interest. In the end it is not even the 1935 Act that triggers decision, but rather Shakespeare.

The actual wording, the absence of quotation marks, integration of the relevant sentence into the judgment, all deserve comment because the role of the drama, King Lear, and the meaning of the intervention border on the enigmatic: "for those who have the inclination to use 'Twitter' for the purpose, Shakespeare can be quoted unbowdlerised, and with Edgar, at the end of King Lear, they are free to speak not what they ought to say, but what they feel."17 Note that Bowdler has lost his capital B, his name, and that the quotation in fact does Bowdlerize both in omitting any context to the quotation and more significantly in adding 'they', personalizing an objective observation of the times, and then a second time by substituting 'they' for 'we'. The folio edition gives us:

Edg. The weight of this sad time we must obey. Speak what we feel, not what we ought to say: The oldest hath born most, we that are young, Shall never see so much, nor live so long. ${ }^{18}$

The truncated and misquoted reference to King Lear is interesting in a dual sense for not doing what it says. As adverted, it Bowdlerizes after explicitly stating that it will not do so. And secondly, more symptomatically, it does what legal interpretation most often does, which is to remove the sentence from its dramatic context where the question at issue is that of succession to the Crown upon the death of King Lear:

Vex not his Ghost, oh let him pass, he hates him, That would upon the rack of this tough World Stretch him out longer.

Succession then in the face of treason and death, where the question, as put by Edgar, is "who has the office?", and who has been "not vanquish'd. But cozen'd, and beguiled." All of which is to say that it is the "sacrifice" of Cordelia, "the judgment of the Heavens that makes us tremble", the deceptions and dissemblances that led to it, and the honour and duplicity of those that would succeed that are in play and provide the context for the quotation, for speaking what we feel. And that is to speak "our woe" and befriend "those that Rule in this Realm". In other words, it is not enough to steal a phrase, part of a sentence, declarative of the will to express our feelings in the face of the demise of the King's body natural, but the judgment also reads Shakespeare in a manner that mirrors the interpretation of the 2003 Act. Neither text is relevant to the tweet in question, neither law nor "Shakespeare's law" provides any direct textual resolution. ${ }^{19}$ While literature necessarily transports and relays all law, the interesting feature of DPP $v$ Chambers is that when the legal text has been recognized, though seldom explicitly, as having run out, literature becomes the legitimation of invention.

\footnotetext{
${ }^{15}$ Chambers $v D P P$, at $156 \mathrm{~h}-\mathrm{j}$.

${ }^{16}$ Chambers $v D P P$, at 156.

${ }^{17}$ Chambers $v$ DPP, at 157.

${ }^{18}$ Shakespeare [1685] (1914).

${ }^{19}$ Though see Desmond Manderson (2008).
} 
Judge Judge writes the law and when pressed to self-conscious invention, his authorship of the new rule leans heavily upon Shakespeare, and literature comes quite literally to play the legislative role. It is a self-conscious moment of jurisliterary intervention and signals unequivocally that when law runs out it is fiction, the imaginal, or in this instance Shakespeare's King Lear that comes explicitly to legislate determination. While this recourse to a play is transgressive of the boundary of law, it is not that unusual. The mot juste, a turn of phrase, maxim or Biblical citation are common in common law judgments when the conflict to be decided is charged and when the subject matter of decision is novel and as yet unspoken by precedent or legislation, as was the case here. We witness then an exception which I argue proves the rule, namely that all juristic writing is jurisliterature and recourse to Shakespeare, to the Bible, to Homer or to Jane Austen simply accentuates the rhetorical visibility of the creative process that is generally so carefully hidden behind the plethora of citations, quotations, Code and case authorities. Shakespeare marks the moment, the punctum of invention, the sudden insight that a joke, badinage, flirtation from one Twitter handle to another, @crazycolours, in a short and poorly punctuated tweet, is not a communication of a menacing character.

\section{TRANSGRESSION UPON TRANSGRESSION}

Transgression transpires to be the norm, and hence its covert character, its umbrageous status in the enchiridion of law. Jurisliterature, the conflation of language and law, literature and legality, imagination and rule, may be most obvious in explicit references to literature and the direct inspiration of creative references but the point is a larger one. Choice of words, language of opening, style of argument, peroration and conclusion are all inventions, plays within and between jurisliterary genres, whether timid or heroic, dry or effulgent. It is in the end always a question of imagination and this can be viewed equally in $D P P \vee$ Chambers in the less striking but nonetheless pertinent apprehension of what the troubled tweet was taken finally to mean. The question is posed as a putatively objective one, not what does 'of a menacing character mean' in subjective terms, as affect, imbrication, and communication to another, but rather what is it from the disembodied perspective of status, authority and legitimacy: "whether a message was menacing should be determined by an objective assessment". ${ }^{20}$ This transpires to mean an inductive exercise, an empirical survey of how officials and public subjectively reacted to the tweet, an inquiry into anxiety or its absence in the twittersphere: "It was posted on 'Twitter' for widespread reading, a conversation piece for the appellant's followers, drawing attention to himself and his predicament ... It seems to us unsurprising, but not irrelevant, that none of those who read the message during the first days after it appeared thought anything of it." ${ }^{21}$ Which is a curious account of objective determination, a reception theory or reader response model of judicial interpretation, although it is evident that the key criterion is that "it seems to us", to Judge Judge and his brothers, Justices Owen and Griffith Williams. From there to a conclusion is but a short step, a small inference or in fact a repetition of the point: "on an objective assessment, the decision of the Crown Court that this 'tweet' constituted or included a message of a menacing character was not open to it" ${ }^{22}$ It is again a curious point in that it was clearly open to the Crown Court Judge to find the message menacing, as the test is simple and subjective, how does it appear to you, and you, and you, and then by way of extrapolation to 'us'. The High Court is simply preferring, in this rather rare instance, to side with the very vocal twittersphere and to act pro populi, and not for 'us' the magistrates and Crown Court judges who begged to differ.

The key point is not the specific subjective assessment of apprehension of menace but rather the jurisliterary process of transgression: from text to twittersphere, from Bench to public opinion, from author of the judgment to auditor of the tweet. Shakespeare is the least of it, a mere symptom of invention and composition which must necessarily move from interior to exterior, both subjectively and in disciplinary genres as well. It is this passage from legal text to social and subjective context that defines authorship and the jurisliterary moment of exploration and experimentation. The boundaries of law and the objectivity of judgment are transgressed time and again, the movement being into theatre, into literature, into theology and philosophy, politics and economics, so as to shore up the abstractions of rule, here a statute based in the regulation of telephone users relations with telephonists in 1935, as applicable to virtualities on the internet and the crowd sourced opinions of microbloggers who virulently protested the conviction of the hapless Chambers caught in his desire for @crazycolours. Transgression upon transgression because the artificiality of the law, itself conceived historically as the predicate of common use, of custom and practice time out of mind, is necessarily an exercise in the fiction of community to which jurisliterature has long contributed and labored to relay.

\footnotetext{
${ }^{20}$ Chambers $v$ DPP, at 149 .

${ }^{21}$ Chambers $v D P P$, at 158 .

${ }^{22}$ Chambers $v D P P$, at 159 .
} 


\section{REFERENCES}

1. Bottomley, A. 2000. "Theory is a Process Not an End", in J. Richardson and R. Sandland (eds), Feminist Perspectives on Law and Theory, London: Cavendish, 2000, pp. 25-51.

2. Brink, C.O.1989. “Quintilian's De Causis corruptae eloquentiae and Tacitus's Dialogus de oratoribus." The Classical Quarterly, 39 (2): 472-503.

3. Carr, H. and Cowan, D. 2016. "What's the Use of a Hashtag? A Case Study", Journal of Law and Society, 43 (3): 416-443. https://papers.ssrn.com/sol3/papers.cfm?abstract_ id=2822558 Accessed 9.4.2020

4. Castañeda, M. 2019. "Virtual Judges in Immigrant Detention: The Mise en Scène of No-show Justice", in Delage, C., Goodrich, P. and Wan, M. (eds.) Law and New Media: West of Everything. Edinburgh: University Press, pp. 169-196

5. Cooper, A. A. [Third Earl of Shaftesbury]. 1999. Characteristics of Men, Manners, Opinions, Times [1714]. Edited by L. E. Klein, Cambridge: Cambridge University Press. http://assets.cambridge.org/052157/0220/frontmatter/0521570220_frontmatter.pdf Accessed 9.4.2020

6. Davies, M. 2017. Law Unlimited. Materialism, Pluralism, and Legal Theory. London: Routledge. https://law.unimelb. edu.au/_data/assets/pdf_file/0018/3109113/1.-DaviesLaw-Unlimited-2017.pdf Accessed 9.4.2020

7. Delage, C., Goodrich, P. and Wan, M. (eds.). 2019. Law and New Media: West of Everything. Edinburgh: Edinburgh University Press.
8. Extabe, J. 2020. "Bakhtin on Language: An Assault on Legal Positivism", forthcoming. Text on file with the author.

9. Justinian, 1985. Digest of Justinian [CE 530-533], edited by A. Watson. Pennsylvania: University of Pennsylvania.

10. Manderson, D. (ed.). 2008. "'As if'-the Court of Shakespeare and the Relationships of Law and Literature", Symposium Issue, Law, Culture and the Humanities, 4 (1): 3-69. https:// www.mcgill.ca/shakespearemoot/files/shakespearemoot/ NotDrowning-FullCase.pdf Accessed 9.4.2020

11. Manderson, D. 2016. "Mikhail Bakhtin and the Field of Law and Literature", Law, Culture, and the Humanities 12 (2): 221-42. https://journals.sagepub.com/doi/ abs/10.1177/1743872112446046 Accessed 9.4.2020

12. McKay, C. 2018. The Pixelated Prisoner: Prison Video Links, Court 'Appearance' and the Justice Matrix London: Routledge.

13. Shakespeare, W. 1914. The Tragedy of King Lear (1685). London: Heinemann. Typography modernised.

14. Tacitus [Publius Cornelius]. 1911. Dialogue on Oratory [102 AD]. London: Loeb Classical Library.

15. Tessier-Ensminger, A. 2015. Fabuleuse juridicité: Sur la littérarisation des genres juridiques. Paris: Garnier.

16. Watson, A. (ed.). 1985. Digest of Justinian [CE 530-533]. Pennsylvania: University of Pennsylvania.

17. Watt, G. 2013. Dress, Law and the Naked Truth. London: Bloomsbury.

18. Weisberg, R. 1992. Poethics and Other Strategies of Law and Literature. New York: Columbia University Press. 